This item was submitted to Loughborough's Research Repository by the author.

Items in Figshare are protected by copyright, with all rights reserved, unless otherwise indicated.

\title{
Integrated use of technologies and techniques for construction knowledge management
}

PLEASE CITE THE PUBLISHED VERSION

http://dx.doi.org/10.1057/palgrave.kmrp.8500154

\section{PUBLISHER}

Palgrave Macmillan (@ Operational Research Society)

VERSION

AM (Accepted Manuscript)

LICENCE

CC BY-NC-ND 4.0

\section{REPOSITORY RECORD}

Ruikar, Kirti, Chimay J. Anumba, and Charles O. Egbu. 2019. "Integrated Use of Technologies and Techniques for Construction Knowledge Management”. figshare. https://hdl.handle.net/2134/8208. 
This item was submitted to Loughborough's Institutional Repository (https://dspace.lboro.ac.uk/) by the author and is made available under the following Creative Commons Licence conditions.

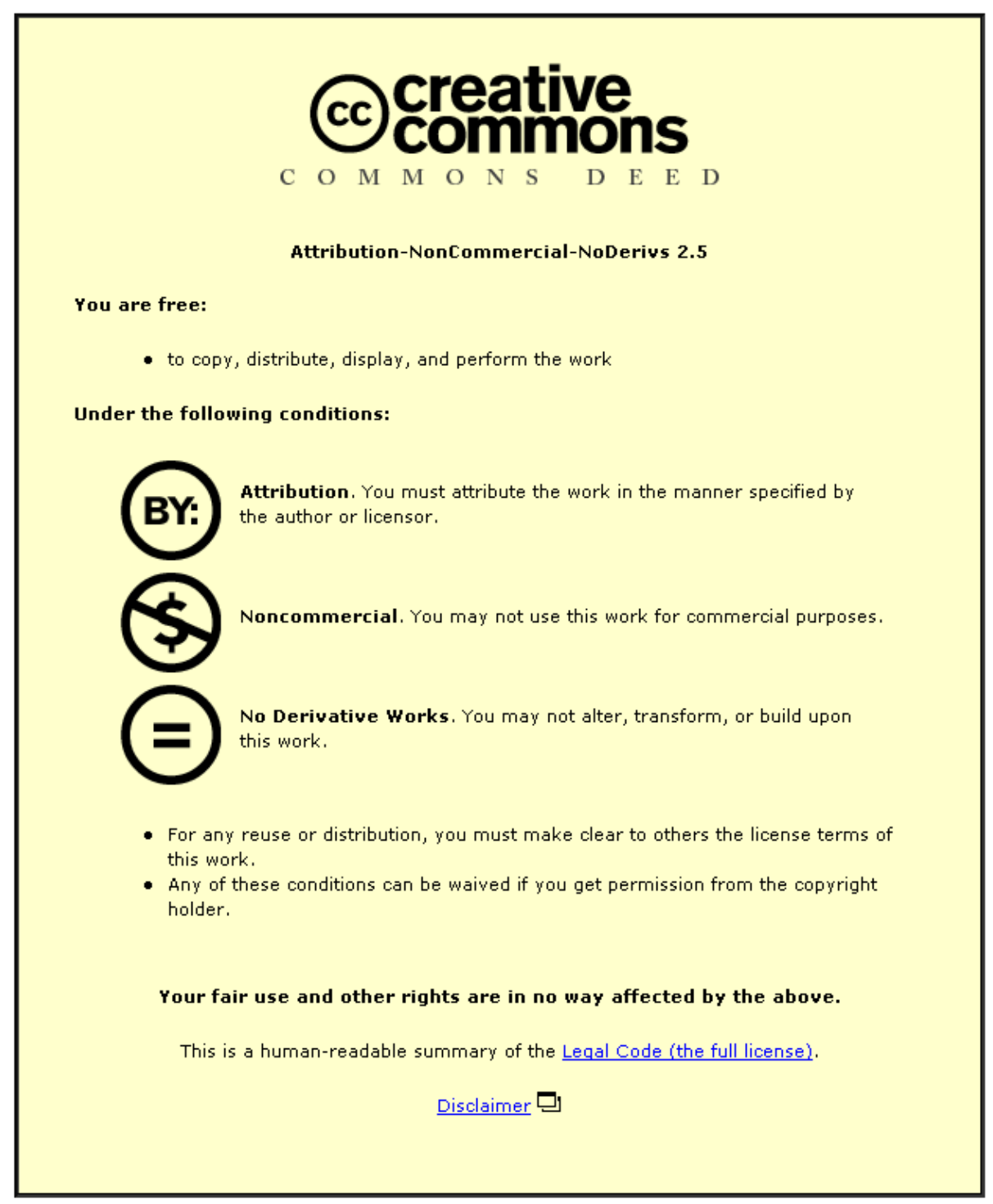

For the full text of this licence, please go to: http://creativecommons.org/licenses/by-nc-nd/2.5/ 
Ruikar, K., Anumba, C. J., and Egbu, C. (2007). 'Integrated use of technologies and techniques for construction knowledge management'. Knowledge Management

Research and Practice 5(4):297-311 2007.

\title{
INTEGRATED USE OF TECHNOLOGIES AND TECHNIQUES FOR CONSTRUCTION KNOWLEDGE MANAGEMENT
}

\begin{abstract}
The last two decades have witnessed a significant increase in discussions about the different dimensions of knowledge and knowledge management (KM). This is especially true in the construction context. Many factors have contributed to this growing interest including globalisation, increased competition, diffusion of new ICTs (information and communication technologies), and new procurement routes, among others. There are a range of techniques and technologies that can be used for knowledge management (KM) in construction organisations. The use of techniques for $\mathrm{KM}$ is not new, but many technologies for $\mathrm{KM}$ are fairly new and still evolving. This paper begins with a review of different $\mathrm{KM}$ techniques and technologies and then reports the findings of case studies of selected UK construction organisations, carried out with the aim of establishing what tools are currently being used in UK construction organisations to support knowledge processes. Case study findings indicate that most organisations do not adopt a structured approach for selecting KM technologies and techniques. The use of KM techniques is more evident compared to $\mathrm{KM}$ technologies. There is also reluctance among construction companies to invest in highly specialised KM technologies. The high costs of specialist KM technologies are viewed as the barrier to their adoption. In conclusion, the paper advocates integrated use of KM techniques and technologies in construction organisations.
\end{abstract}

Keywords: Knowledge Management, Case Studies, KM Techniques, KM Technologies and UK Construction 


\section{INTRODUCTION}

The fact that the 'Knowledge Management' has emerged only since the mid-1990s hints strongly at underlying dilemmas and fundamental issues. On the one hand, the apparent lack of interest in knowledge management pre-1995 suggests that either the subject was thought unimportant or unmanageable. On the other hand, it is patently obvious that knowledge processes occurred in organisations pre-1995, and in one way or another were 'managed', whether or not these processes were formally labelled Knowledge Management (KM). Indeed, much of the recent interest in $\mathrm{KM}$ focuses on the discovery of existing informal knowledge processes such as storytelling, and existing knowledge structures such as informal communities of practice, rather than the design of new processes or structures (Chataway, et al 2003; and Quintas 2005). In the construction context, the last two decades have witnessed a significant increase in discussions about the different dimensions of knowledge and knowledge management. Globalisation, increased competition, diffusion of new ICTs (information and communication technologies), and new procurement routes are some of the factors that have contributed to this growing interest (Egbu et al., 2005; and Quintas, 2005).

There are a number of definitions of KM that are applicable in the construction context. Broadly, KM is an innovative way in which organisations retain and reuse corporate memory to gain strategic and competitive advantage. KPMG (1998) define KM as a systematic and organised attempt to use knowledge within an organisation to transform its ability to store and use knowledge to improve performance. Others define $\mathrm{KM}$ as the process through which organisations can generate value from their intellectual and knowledge-based assets (Santosus and Surmacz, 2001). More often than not, generating value from such assets involves sharing these with employees, across departments and even with other companies in an effort to devise best practice. It is, however, important for organisations to recognise that $\mathrm{KM}$ is not only about sharing knowledge (Carrillo, et. al., 2001), it also involves other processes. Nissen, et al (2000) tabulate and compare the different KM lifecycles proposed by several researchers and experts which share considerable similarities. They call attention to the fact that although the KM lifecycle is generally described as a sequence of activities, in practice the process is iterative, as each activity is often revisited numerous times. When broadly considered, however, KM comprises processes such as locating and accessing, capturing and storing, representing, sharing and creating new knowledge (see Figure 1), which have been described by Kamara et al. (2002) as the most commonly used processes in UK construction organisations and are hence used in the context of this paper. 


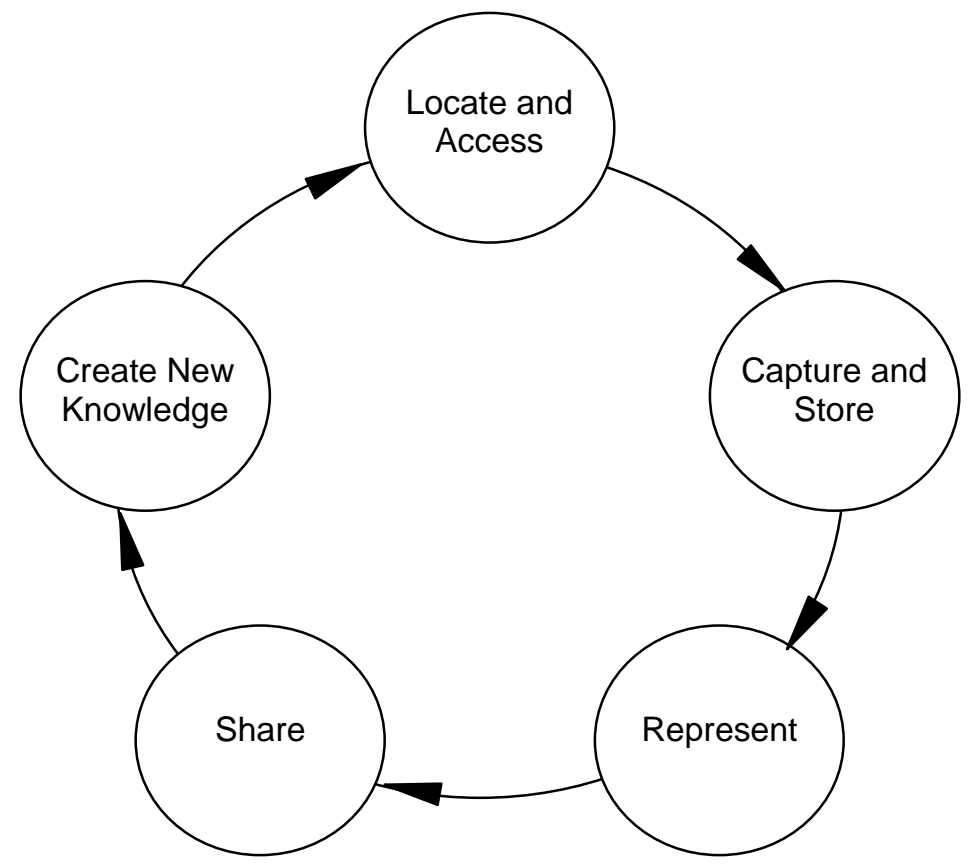

Figure 1. Knowledge Management Processes

\section{KNOWLEDGE MANAGEMENT TOOLS}

Knowledge management tools include both techniques (mainly non-IT tools) and technologies (IT tools). KM tools are not simply information management tools as they should be 'capable of handling the richness, the content, and context of the information and not just the information itself' (Gallupe, 2001). For this research, both informal knowledge processes and formalised KM initiatives are considered with the aim of adopting an approach that attempts to deal with knowledge, rather than any proxies, such as information. Many accounts of KM default to a focus on information management. Such a view underestimates the richness of the subject of knowledge, and the opportunities a knowledge focus offers for re-thinking business processes. Whereas certain types of knowledge can be codified and treated as information, much knowledge is personal, being based on experience and reflection, and remains tacit (Polanyi 1958, 1966). Conversely, knowledge also has a social dimension, being created and shared in social groupings, within which tacit knowledge sharing occurs (Brown and Duguid, 1991). Related to its social nature, knowledge is also created in specific contexts, and is to varying degrees 'situated' (Lave and Wenger, 1991) or context specific, and may be 'sticky' and difficult to transfer or share (von Hippel,1994). As noted above, this reduces the potential for the simple and costless transfer of lessons learned between contexts, such as companies or industries. 
A popular definition by Ruggles (1997) describes KM tools as the technologies used to enhance and enable the implementation of the sub-processes of KM (e.g. knowledge generation, codification, and transfer). He identifies that not all KM tools are IT-based, as everyday tools such as papers, pens, and videos can be utilised to support $\mathrm{KM}$. In fact, most authors use the term KM tools to refer to the technologies used for KM. In this paper, KM tools will be used to describe both non-IT tools and IT tools. To distinguish between the two, the terms 'KM techniques' and 'KM technologies' are used for 'non-IT KM tools' and 'IT KM tools' respectively. The main differences between KM techniques and technologies are presented in Table 1 and discussed thereafter.

Table 1. KM Tools: Comparison between KM Techniques and Technologies (Al-Ghassani, 2002)

\begin{tabular}{ll}
\multicolumn{1}{c}{ KM Techniques } & KM Tools \\
\hline \hline & \multicolumn{1}{c}{ KM Technologies } \\
\hline \hline - Require strategies for learning & - Require IT infrastructure \\
- More involvement of people & - Require IT skills \\
- Easy to implement and maintain & - Expensive to acquire/maintain \\
- More focus on tacit knowledge & - More focus on explicit knowledge \\
\hline \hline
\end{tabular}

While KM processes are often facilitated by IT, technology by itself is not KM. Information technology is concerned with information and not knowledge per se (Quintas, 2005). In the context of KM, both technologies and techniques are equally important to support different KM processes. KM techniques do not depend on IT but provide support in some cases. For example, knowledge sharing can take place through face-to-face meetings, recruitment, apprenticeships, mentoring, training, and other techniques. The importance of techniques comes from several factors. KM techniques are affordable to most organisations as no sophisticated infrastructure is required. Also, KM techniques are easy to implement and maintain due to their simple and straightforward nature. KM technologies, on the other hand, depend on an IT infrastructure.

\section{KM TECHNOLOGIES}

$\mathrm{KM}$ technologies rely on an IT infrastructure. Examples of $\mathrm{KM}$ technologies for capturing knowledge are Knowledge Mapping Tools, Knowledge Bases, and Case-Based Reasoning. Although there is a debate about the degree of importance of such technologies, many organisations consider these very important enablers that support the implementation of a KM strategy (Skyrme and Amidon, 1997; Kanter, 1999; Anumba et al, 2000; Egbu, 2000; Storey and Barnet, 2000) as they consume one third of the time, effort and money required for a KM system. 
The other two-thirds mainly relate to people and organisational culture (Davenport \& Prusak, 1998; Tiwana, 2000).

KM technologies consist of a combination of hardware and software technologies. Hardware technologies and components are important for a KM system as they form the platform for software technologies to perform and are the medium for storage and transfer of knowledge. Some of the hardware requirements of a KM system include personal computers or workstations to facilitate access to knowledge, powerful servers to allow the organisation to be networked, open architecture to ensure interoperability in distributed environments, media-rich applications requiring Integrated Services Digital Network (ISDN) and fibre optics to provide high speed and use of the public networks (e.g. Internet) and private networks (e.g. Intranet, Extranet) to facilitate access to and sharing of knowledge (Lucca et al, 2000). Software technologies play an important part in facilitating the implementation of $\mathrm{KM}$. The number of software applications has increased considerably in the last few years. Solutions provided by software vendors take many forms and perform different tasks. The large number of vendors that provide KM solutions makes it extremely difficult to identify the most appropriate solutions. This has resulted in organisations adopting different models for establishing KM systems. Tsui (2002b) identifies five emerging models for deploying organisational KM systems where one or a combination may be adopted:

- Customised Off The Shelf (COTS) - This is the traditional and most popular way of deploying application services. Based on the organisational needs, the applications will be identified and then examined against the functional needs of the organisation. A shorttest period may follow to identify the most suitable application. Once an application is acquired, customisation of the standard features is performed to integrate it into the organisation's information system;

- In-house Development - These systems are developed within the organisation, usually with external technical help. Examples are Notes, Domino, and Intranet applications. This option is generally less attractive to organisations for reasons such as the difficulty of establishing KM systems requirements, high-cost, risk, and the complexity of developing bespoke systems;

- Solution Re-engineering - This involves adapting, with the help of KM consultants and technical architects, an existing generic solution that matches the organisation's requirements. Although similar to COTS, the adapted solution is not packaged as a product that can be marketed. Examples are online knowledge communities, and virtual collaboration tools; 
- Knowledge Services - These are knowledge applications provided by a third party that hosts the application on the Web. The user accesses the service via a thin-client (e.g. a browser). The main benefits are the waived software licensing fee and the avoidance of in-house maintenance. Many organisations, however, do not find this option attractive because of associated security and privacy issues; and

- Knowledge Marketplace - Modelled on the E-business NetMarket concept, several knowledge-trading places have been established. In a Knowledge Marketplace, a third party vendor hosts a Web site grouping together many suppliers of knowledge services. Suppliers may include expert advisors, vendors providing product support services, KM job placement agencies, procedures for the evaluation of $\mathrm{KM}$ and portal software, and research companies providing industry benchmarks and best practice case studies.

KM software technologies have seen many improvements since the year 2000 due to many alliances, and mergers and acquisitions between KM and Portal tool vendors (Tsui 2002b). None of them, however, provide a complete solution to KM. These tools are better described within technology groups such as data and text mining and groupware. Table 2 describes the different KM software technologies and their uses (Haag and Keen, 1996; Haag et al, 1998; and Tsui, 2002 a \& b).

Table 2. Some KM Software Technologies and Their Uses.

\begin{tabular}{ll}
\hline \hline $\begin{array}{l}\text { KM Software } \\
\text { Technologies }\end{array}$ & \multicolumn{1}{c}{ Description and Uses } \\
\hline \hline $\begin{array}{l}\text { Data and Text } \\
\text { Mining }\end{array}$ & $\begin{array}{l}\text { Technology for extracting meaningful knowledge from masses of data or text } \\
\text { - } \\
\text { Enables identification of meaningful patterns and associations of data (words and } \\
\text { phrases) from one or more databases or 'knowledge bases'. }\end{array}$ \\
& - $\begin{array}{l}\text { Enables identification of hidden relationships between data and hence creating new } \\
\text { knowledge. }\end{array}$ \\
& $\begin{array}{l}\text { Used in business intelligence, direct marketing and customer relationship } \\
\text { management applications. }\end{array}$
\end{tabular}

Groupware - Supports distributed and virtual project teams where team members are from multiple organisations and in geographically dispersed locations.

- Enables effective and efficient communication and sharing of information for geographically dispersed project teams.

Intranet - An internal organisational Internet that is guarded against outside access by special security tools called firewalls.

- Used for storing, sharing, accessing and locating company documents and information such as H\&S standards, procedures, press releases, etc.

Extranet - An Intranet with limited access to outsiders, making it possible for them to collect and deliver certain knowledge on the Intranet.

- Useful for making organisational knowledge available to geographically dispersed staff members. 


\begin{abstract}
Knowledge - Repositories that store knowledge about a topic in a concise and organized manner. Base - They present facts that can be found in a book, a collection of books, web sites or even human knowledge. This is different from the knowledge bases of expert systems, which incorporate rules as part of the inference engine that searches the knowledge base to make decisions.

Taxonomies and Ontologies

- Taxonomy is a collections of terms (and the relationships between them) that are commonly used in an organisation. Examples of a relationship are 'hierarchical' (where one term is more general hence subsumes another term), 'functional' (where terms are indexed based on their functional capabilities), and 'networked' (where there are multiple links between the terms defined in the taxonomy).

- Ontologies also define the terms and their relationships but additionally, they support deep (refined) representation (for both descriptive and procedural knowledge) of each of the terms (concepts) as well as defined domain theory or theories that govern the permissible operations with the concepts in the ontology.

- $\quad$ Both can be used as corporate glossaries to hold detailed descriptions of key terms used in an organisation. They can also be used to constrain the search space of search engines and prune search results, identify and group people with common interests, and act as a content/knowledge map to improve the compilation and real time navigation of Web pages.
\end{abstract}

\title{
KM TECHNIQUES
}

$\mathrm{KM}$ techniques do not depend on IT although they provide support in some cases. Knowledge sharing, for example, is a sub-process of $\mathrm{KM}$, which can take place through face-to-face meetings, recruitment, apprenticeships, mentoring, and training. The importance of KM techniques comes from several factors (see Table 1). Firstly, KM techniques are affordable to most organisations as no sophisticated infrastructure is required. Some techniques, however, require more resources than others (e.g. training requires more resources than face-to-face interactions). Secondly, KM techniques are easy to implement and maintain due to their simple and straightforward nature. Thirdly, KM techniques focus on retaining and increasing the organisational tacit knowledge, a key asset to organisations.

KM techniques are not new, most organisations have been implementing these for a long time under the umbrella of management approaches such as organisational learning and learning organisations. Using these tools for management of organisational knowledge requires their use to be enhanced so that benefits, in terms of knowledge gain/increase, can be fully realised. Examples of KM techniques include brainstorming, communities of practice (CoPs, face-to-face interactions, post-project reviews, recruitment, mentoring, apprenticeship and training. Some of the KM techniques are more formal than others. On the one hand are face-to-face interactions which are useful for sharing the tacit knowledge owned by an organisation's employees. It is an informal and a powerful approach that helps in increasing the organisation's memory, developing 
trust and encouraging effective learning. Face-to-face interactions provide strong social ties and tacit shared understandings that give rise to collective sense-making (Lang, 2001), which in turn leads to an emergent consensus as to what is valid knowledge and to the serendipitous creation of new knowledge and, therefore, new value. Training, on the other hand, usually follows a formal format and can be internal where seniors train juniors within the organisation, or external where employees attend courses managed by professional organisations or experts. The successful implementation of a training programme relies on careful planning and defined strategies.

Some other forms of KM techniques such as brainstorming and CoPs rely on groups for collective 'thinking' or problem solving. Brainstorming, for example, requires a group of individuals to focus on a problem and intentionally propose as many deliberately unusual solutions as possible through pushing the ideas as far as possible. The participants discuss ideas and then build on these ideas. Only when the brainstorming session is over are the ideas evaluated (Tsui $2002 a$ \& b). Communities of practice consist of a group of people with different skill sets, development histories and experience backgrounds that work together to achieve commonly shared goals (Ruggles, 1997). Members of CoPs may perform the same job or collaborate on a shared task (software developers) or work together on a product (engineers, marketers, and manufacturing specialists). They are peers in the execution of "real work." What holds them together is a common sense of purpose and a real need to know what the other knows. Usually, there are many CoPs within a single company and most people normally belong to more than one. CoPs are sometimes referred to as knowledge communities, knowledge networks, learning communities, communities of interest and thematic groups.

\section{CASE STUDY RATIONALE}

$\mathrm{KM}$ is of particular significance to the UK construction industry, as effective management of corporate knowledge can help organisations to improve performance and efficiency This is especially important given that time and again several construction review reports have urged the construction industry, UK's largest industry responsible for about 8\% of GDP, to improve its performance through novel ways of working (Latham, 1994; and Egan, 1998). Although there is growing awareness and interest in KM in the UK construction industry, it is evident that KM is still in its infancy in this sector (Carrillo, 2001; and Hari, et. al., 2003). Construction organisations are often reluctant to invest in new initiatives or innovative approaches citing low profit margins often mitigating against investment in research and development (Robinson et al, 2001).

According to a recent study (Egbu and Robinson, 2005) KM and its manifestation in the expertise of people is now seen as the greatest value of creation for organisations. It is an innovative approach increasingly seen as a source of competitive advantage enabling organisations to effectively, creatively and consistently use their intellectual capital/assets to 
improve business performance and customer satisfaction (TFPL, 1999). The transition to a knowledge economy has had an effect on many industries. Professional service firms, particularly management consultancies whose primary product is knowledge are among the first to make significant investments in the management of knowledge (Hansen, Nohria and Tierney, 1999). Industries such as construction are beginning to follow suit as knowledge is widely recognised as a powerful asset and a source of competitive advantage to improve business performance.

A range of techniques and technologies can be used for knowledge management in construction organisations. Some of the techniques are not new, but most technologies are relatively new and are still evolving. A survey of 170 UK construction organisations carried out at Loughborough University (Carrillo et al, 2002) indicated that communities of practice is the most widely used technique for $\mathrm{KM}$, particularly in large organisations. Large construction organisations with a range of specialist skills tend to have the need and resources to set up communities of practice. Brainstorming, job observation and rotation systems, research collaboration, conferences and seminars are also commonly used KM techniques. Small construction organisations identified conferences and seminars as effective mechanisms for knowledge sharing and accessing to up-to-date knowledge in the field. Technologies, such as the Intranet are regularly used as a platform for knowledge sharing, particularly in large construction organisations with geographically dispersed branches with diverse knowledge to share. Other popular technologies are document management systems (e.g. Documentum and Sage Desk), groupware (e.g. Lotus Notes, Lotus Quickplace, Live Link and e-Room) and taxonomy tools (e.g. Autonomy). The use of these technologies may increase as collaborative working becomes more important in the construction supply chain. Extranets and electronic discussion forums are used to a limited degree.

The limited number of studies seem to focus on the 'explicit' aspect of knowledge rather than the 'tacit' aspect. The issue of tacit knowledge and the very important social dimensions are often ignored. Yet, there is strong evidence to suggest that it is the tacit knowledge that contributes to organisational innovations and competitiveness (Scarborough et al, 1999; Egbu, 1999; Robinson et al, 2001) and which is difficult to imitate. Arguably, the importance of tacit knowledge is particularly relevant in the context of the construction industry where manual skills and other forms of accumulated knowledge acquired through experiential learning retain their importance. There, however, seem a meagre amount of empirical studies conducted on KM in the UK construction industry. In order to investigate this argument and supplement the information obtained from the survey (Carrillo et al, 2002), case studies were carried out with five UK construction companies. The strength of case study research lies particularly when the aim is to obtain a detailed contextual view of a particular phenomena (Yin, 1994), in this case investigating (and informing) KM practices in construction organisations. The objective of such a study is 
manifested in the definition of a case study by Yin (1994) who describes a case study as "an empirical inquiry that investigates a contemporary phenomenon within its real-life context, especially when the boundaries between phenomenon and context are not clearly evident". The weakness of case studies, however, is that they are restricted to a single individual or organisation or just a few and therefore may not be representative of the general group or population and it is, therefore difficult to generalise from case study research. Bearing this in mind, this paper does not set out to be 'prescriptive' but on the contrary, 'informative' relying on 'deductive' application of lessons learnt in of context of an organisation and its unique characteristics and dynamics.

Case studies conducted aimed to establish the techniques and technologies used to support key knowledge processes in UK construction companies and the degree of usefulness of these. This was done primarily through semi-structured interviews with knowledge managers of five UK construction organisations (see Table 2). Typically, each interview lasted between 45 minutes to an hour and each interviewee was supplied with a generic questionnaire that was used as a guideline for the interviews. The questionnaire included a list of possible technologies and technologies (see Table 3) for managing the following KM processes:
o Locating and Accessing,
o Capturing and Storing,
o Representing,
o Sharing, and
o Creating New Knowledge.

Table 3. Background of Case Study Companies and Roles of Interviewees

\begin{tabular}{clll}
\hline \hline Company & \multicolumn{1}{c}{ Company Type } & $\begin{array}{l}\text { No. of } \\
\text { Employees }\end{array}$ & Employee: Role within Company \\
\hline \hline Company 1 & Professional Services Consultancy & $>500$ & E1: Knowledge Development Mgr. \\
Company 2 & Construction Services Organisation & $>500$ & E2: Knowledge Manager \\
Company 3 & Infrastructure Contractor & $>500$ & E3: KM Programme Director \\
Company 4 & Design and Business Consulting & $>500$ & E4: Group Knowledge Manager \\
Company 5 & Construction Services Organisation & $>500$ & E5: Knowledge Manager \\
\hline \hline
\end{tabular}


Table 4. KM Technologies and Techniques to Support KM Processes

\begin{tabular}{|c|c|c|}
\hline 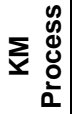 & $\begin{array}{c}\text { KM Technologies } \\
\text { (Application Software) }\end{array}$ & KM Techniques \\
\hline 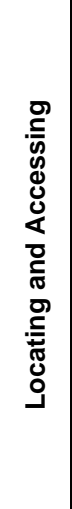 & $\begin{array}{ll}\text { - } & \text { Experts Directory: AskMe, Sigma Connect, IntellectExchange, Expertise } \\
\text { - } & \text { Infrastructure } \\
\text { - } & \text { Data Warehouses: Syncsort: } \\
\text { - } & \text { Web Crawler: Meta Search: MetaCrawler, SurfWax, Copernic Basic 2001, } \\
& \text { Livelink, Dogpile, Mamma, CNET Search } \\
\text { - } & \text { Data Mining: Knowledge SEEKER, RetrievalWare, XpertRule Miner, Clementine } \\
\text { - } & \text { Text Mining: SemioMap, Intelligent Miner for Text, Megapture Intelligence } \\
\text { - } & \text { Knowledge Mapping - Concept Mapping: Knowledge Service, IHMC Concept } \\
& \text { Map, Knowledge Discovery Packages, Knowledge Discovery Tools by Lotus } \\
& \text { IBM, Livelink by OpenText } \\
\text { - } & \text { Intranet/Extranet: Livelink, Instant Intranet Builder, iLevel, } \\
- & \text { Search Engines: Google, Yahoo, FAST, Excite, AltaVista, Infoseek } \\
- & \text { Taxonomy/Ontological Tools: Autonomy, SemioMap, RetrievalWare Suite } \\
- & \text { Web Mapping Tools: Web Squirrel, WINCITE } \\
- & \text { Electronic Document Management Systems: Documentum, BASIS } ®, \text { Dicom } \\
- & \text { Electronic Mail: Eudora, Microsoft Outlook }\end{array}$ & $\begin{array}{ll}\text { - } & \text { Recruitment } \\
\text { - } & \text { Yellow Pages } \\
\text { - } & \text { Libraries }\end{array}$ \\
\hline : & $\begin{array}{ll}\text { - } & \text { Word Processors: MS Word, Word Perfect } \\
\text { - } & \text { Case-Based Reasoning - Expert Systems: CBR-Works, Kaidara } \\
\text { - } & \text { Knowledge Bases: Assistum, KnowledgeBase.net, XpertRule Knowledge Builder } \\
\text { - } & \text { Knowledge Mapping - Concept Mapping: Knowledge Service, IHMC Concept } \\
& \text { Map }\end{array}$ & $\begin{array}{ll}- & \text { Post project } \\
\text { - } & \text { Reviews } \\
\text { - } & \text { Recruitment } \\
\text { - } & \text { Discussion forums } \\
\text { - } & \text { Mraining }\end{array}$ \\
\hline 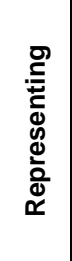 & $\begin{array}{ll}\text { - } & \text { Mind Mapping Applications -Brainstorming: Mind Manager, The Brain } \\
\text { - } & \text { Web Publishing: KnowledgeBase.net } \\
\text { - } & \text { Virtual Reality Tools: Maelstrom, 3ds max }{ }^{\mathrm{TM}} \text { for Windows } \\
\text { - } & \text { Word Processors: MS Word, Word Perfect } \\
\text { - } & \text { Computer Aided Design: Autodesk products } \\
\text { - } & \text { Spread-Sheets: MS Excel, StarOffice/OpenOffice Calc, Lotus 1-2-3 } \\
\text { - } & \text { Knowledge Mapping - Concept Mapping: Knowledge Service, IHMC Concept } \\
\text { Map }\end{array}$ & $\begin{array}{ll}- & \text { Drawings } \\
- & \text { Diagrams } \\
- & \text { Notes } \\
- & \text { Concept maps }\end{array}$ \\
\hline 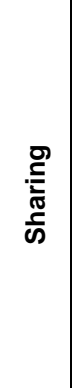 & $\begin{array}{ll}\text { - } & \text { Web Publishing: KnowledgeBase.net } \\
\text { - } & \text { Communities of Practice: AskMe } \\
\text { - } & \text { Intranet/Extranet: Livelink, Instant Intranet Builder, iLevel } \\
\text { - } & \text { Web-Based File Sharing: KnowledgeDisk, Briefcase } \\
\text { - } & \text { Instant Messaging: NetLert3 Messenger, Trusted Messenger, ICQ, AOL } \\
\text { - } & \text { Instant Messenger, Yahoo Messenger, MSN Messenger } \\
& \text { Integrated Groupware Solutions: Lotus (Notes, Domino, Sametime, } \\
& \text { QuickPlace), GroupWise, BrightSuite Enterprise, MyLivelink, Plumtree } \\
\text { Collaboration Server, iTeam, iCohere } & \\
\text { - } & \text { Multi-Media - Video Conferencing software:MS NetMeeting, AbsoluteBUSY, } \\
\text { - } & \text { ERoom, WebEx Training Center, WebEx, Meeting Center, WebDemo } \\
\text { Electronic Mail: Eudora, MS Outlook, etc }\end{array}$ & $\begin{array}{ll}- & \text { Communities of } \\
\text { - } & \text { Practice } \\
& \text { Face-to-face } \\
\text { - } & \text { Interactions } \\
- & \text { Apscussion Forums } \\
- & \text { Mentoriceship } \\
- & \text { Training } \\
- & \text { Seminars } \\
- & \text { Conferences }\end{array}$ \\
\hline 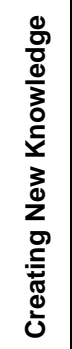 & 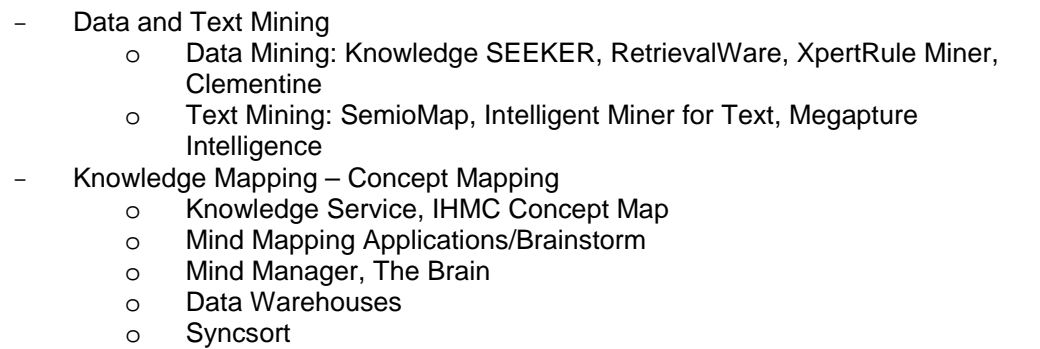 & $\begin{array}{l}\text { - } \quad \text { Brainstorming } \\
\text { - } \quad \text { Project team/Supply } \\
\text { chain face-to-face } \\
\text { meetings }\end{array}$ \\
\hline
\end{tabular}


In addition to the above questions the interviewees were also asked to identify how specific technologies and techniques were selected. Interviewees were asked about knowledge processes that occur naturally, such as the sources of knowledge for problem-solving and creative work. This device sought to invite discussion of informal knowledge processes as well as those that may be considered formal knowledge management. The analysis of the data thus collated was done qualitatively. The remainder of this paper presents an analysis of the findings of these case studies.

\section{LOCATING AND ACCESSING KNOWLEDGE}

With regards to locating and accessing knowledge, the case study findings are hardly surprising where it was evident that most case study organisations do not follow a formalised structure for locating and accessing knowledge. It is also evident that the effectiveness of locating and accessing knowledge relies on the knowledge and experience of the individual seeking that knowledge. E3 a KM programme director, for example, points out the significance of experience and describes how easily knowledge can be located when individuals working on projects are faced with problems similar to those encountered on projects they previously worked on. In such cases, project knowledge bases comprising project logs and project reviews can be accessed by either contacting project team members or retrieving project archives. E3 points out the possible disadvantage new recruits are at due to a lack 'insider knowledge' or inexperience. Company 3 has effectively addressed this potential issue by adopting the mentoring technique and assigning experienced mentors for providing guidance and support to new employees.

As expected, there are a number of technologies and techniques currently available for supporting the KM processes of locating and accessing knowledge. The case study organisations sometimes use a combination of technologies and techniques to locate and access knowledge. For example, information about suppliers is located using both electronic and non-electronic directories and knowledge about suppliers (competency, responsiveness, etc) is accessed by directly contacting employees who have previously worked with the supplier. E-mailing is also another effective technique used by most case study companies to seek subject- or projectspecific solutions. E4, for example, sends a company-wide email requesting information or expertise on specific construction problems. Once this is responded to (or located), common techniques such as face-to-face meetings can be used to access this knowledge.

Technologies for Locating and Accessing Knowledge: The degree of IT usage for locating and accessing knowledge varies from company-to-company. Generally, IT is viewed as a 'means to an end'. Also, these companies are neither commercially-conscious nor cost-conscious and prefer a low-tech approach to knowledge management due to the relative difficulty in justifying the high costs of implementing specialised software tools (see Exhibit 1). This is 
especially true if the net gain is small compared to the overall cost of investment. These results echo the findings of other research studies (Egbu, 2000), where it was seen that the set-up costs, maintenance costs and the level of expertise associated with some KM technologies prohibited their wider use in construction organisations. Most construction companies have a techno-phobic attitude and adopt technology if only there are definite, quantifiable business benefits which stretch across the company. Only construction companies that view technology as a forerunner in innovation have dedicated IT departments with in-house software development teams to develop software for supporting KM processes.

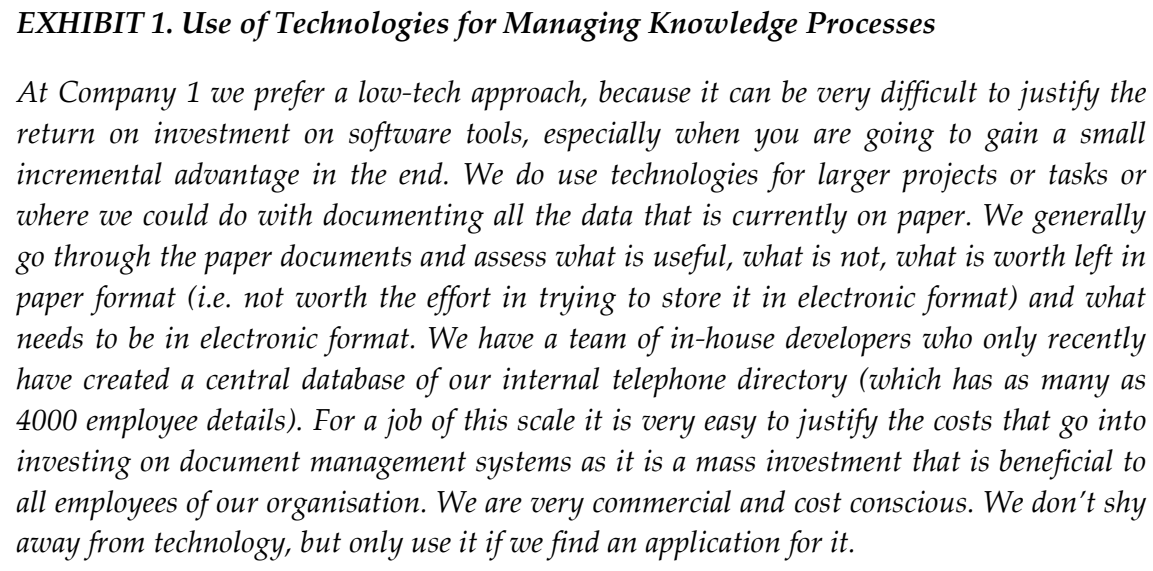

Search engines, intranets, extranets, e-mail and document management systems are some of the IT tools used to locate and access knowledge. Internet-based search engines like Google are used by most case study companies to locate information that covers a vast range of topics from general day-to-day news items to construction-specific publications and reports. In most case study organisations intranets play an important role in locating and accessing knowledge. Their use, however, varies from company-to-company. Company 3 uses the company intranet to store internal information about the different company regions, internal vacancies, staff notices and staff directories. Most case study companies use company-wide intranets for recruitment. Staff vacancies, for example, are advertised on company intranets to encourage existing staff who are seeking new challenges within the broader organisation to apply. Intranet-based staff directories are used to identify and locate staff with specialised skills and expertise (e.g. Tunnel design experts). Company 3 is developing electronic yellow pages with links to staff Web pages displaying information such as contact details, brief bio-data, areas of interest, skills and specific areas of expertise. Such Web-based yellow pages facilitate and simplify the task of locating and accessing company-wide knowledge. 
In Company 5, intranets hold documents such as project reports, company standard forms, $\mathrm{H} \& \mathrm{~S}$ standards, performance indicators and other administrative documents such as leave application forms and requisition forms. These intranets provide external links to useful construction Web sites such as electronic construction journals and magazines, and other similar knowledge sources.

Project extranets are being increasingly used in case study companies as they are considered an important project knowledge base that can be easily accessed by geographically dispersed project teams. However, as pointed out by E2, only authorised staff can access data from these knowledge bases. In his view, often these security measures inadvertently restrict access to knowledge and therefore project information is only available to those individuals directly involved in the project leaving companies with large knowledge repositories that only few can access. E2 highlighted the need for this information to be readily available across project boundaries to avoid mistakes being repeated.

Techniques for Locating and Accessing Knowledge: Not surprisingly, most case study organisations do not have a standard procedure or system in place for locating or accessing knowledge. Non-IT tools such as yellow pages, libraries and recruitment are some of the commonly used techniques for locating and accessing knowledge. When there is a need to learn more about a new area, companies access that knowledge through subscribing to or purchasing written or electronic media such as journals, newsletters and technical reports. However, how effectively that knowledge is applied depends on the absorption capacity, competency and ability of the individual/s seeking that knowledge.

The type of technique used to locate knowledge depends on the type of knowledge sought e.g. people are located by advertising and recruiting; and books and published documents are accessed using libraries, subscription or purchase. Also, the effectiveness of these techniques depends on the market situation, for instance, for companies with bad press the responses to adverts/vacancies may be poor. Companies often adopt a range of measures to access knowledge. Company 2, for instance, locates new knowledge by publishing vacancies in company newsletters. The effectiveness of this system can, however, be unpredictable as it can be difficult to gauge whether this information actually reaches every project and/or department. Also, the most knowledgeable people may not necessarily respond to the adverts.

There are other examples of innovative ways in which knowledge is located and accessed. Company 1, for example, uses 'creditation' (a self assessment mechanism) using which members of staff grade their levels of expertise. Grades range typically from $A$ to $E$, where $\mathrm{A}=$ general awareness, $\mathrm{C}=$ competence, and $\mathrm{E}=$ expertise. $\mathrm{A}$ member of staff, for example, may view himself/herself as an expert project manager, with very good people skills who is skilled at building teams and elevating team morale. Having assessed their own capabilities these are then 
verified by their line managers to ensure the validity of the claims and verify whether the staff member being assessed in fact demonstrates those skills and competencies. The final assessment report is distributed across the company and can be accessed by those seeking individuals' with a particular talent or level of expertise, for example, staff demonstrating good people skills can be particularly effective in situations where teams working is essential. Such a skills database can be beneficial to all and can provide to be an effective way of ensuring that only the most efficient staff are used to resolve issues and pursue opportunities.

EXHIBIT 2. Techniques Used by Company 1 to Locate New Knowledge

We use several techniques to capture knowledge. Things that work are used and we do not have a structured approach for this process. As organisations grow larger we have the opportunity to chose who we want to employ to locate new knowledge. If you take the example of the health sector, for example, we might think it more appropriate to recruit a nurse to find out the 'insides' of the working. For example, what does a nurse do? What/who influence/s her/his work? What is a typical day in a nurse's life? This knowledge adds a new dimension to the story. However, it is then my role as a Knowledge Development Manager, to transfer this knowledge to my colleagues or company in a way that is best understood by them.

\section{CAPTURING AND STORING KNOWLEDGE}

The practice of capturing and storing corporate knowledge is beneficial to companies as it provides valuable insight into project knowledge and may be re-used for future projects as applicable. Such practices of recording valuable experiences in electronic (or other) formats can be useful to avoid repeating past mistakes. By capturing tacit knowledge it is possible to retain corporate memory, as the inability to do so risks loosing it for good, especially when senior members of staff leave or retire. This can create a void that cannot be filled easily. Once knowledge has been captured it is vital to ensure that it is up-to-date. Company 1 holds periodic reviews and appraisals to ensure that only correct knowledge is stored. The other case study organisations, however, do not adopt a definite strategy to ensure validity of the knowledge stored. E1 and E4, disagree that there is a need for a defined strategy. In their view, individuals can use their experiences, discretion, and judgements to ensure that a piece of information or document is accurate. Only if it is deemed accurate will it be used or referred to. Adopting such a 'discretionary' approach, however, relies on the individual's ability and therefore limited in that respect. To others (E2, E3 and E5), technology can be used to prompt reviews and revisions. For example, in order to ensure that a published document is up-to-date, the initiator/publisher of the document can set a review date to automatically prompt checks on validity and accuracy of the data published. This, however, does not ensure that the document is updated. 
Technologies for Capturing and Storing Knowledge: Technologies used for capturing and storing knowledge include word processors, knowledge bases and case-based reasoning tools. Word processors are commonly used for knowledge capture and storing. In most case study companies, information is captured and documented using software applications such as MS Word or Excel. This information is made available to all company employees over the intranet. Typically, these are generic documents such as standard company policies and procedures, administrative forms and design guides. Most case study organisations do not document information about projects, however, most now recognise the value of such project knowledge and are adopting measures for capturing and storing such data. They recognise the need for company intranets to hold more project-specific documents describing projects, their performance (including successes and failures), recommendations made at the end of the project, the performance of individual project partners and any other information considered to be of value. This knowledge-base is viewed as being of considerable value, especially for future projects.

Some case study organisations are more confident in their ability to use technologies than others. Company 3, for example, uses intelligent data capture (and management) systems to capture and store Health and Safety $(H \& S)$ related information. The system not only maintains records of H\&S incidents, but also helps to carry out statistical analysis of captured data and establishes patterns and commonalities i.e. makes sense of recorded data. This, for example, is related to the type of incident that occurred, whether this type of incident occurs only for a particular type of sub-contractor or project. Such an analysis can provide valuable insight into a project's successes and failures.

Some case study companies (Companies 1 and 5) have in-house software development teams that focus on automating existing processes. Sometimes, the outcome of such development is a highly sophisticated and specialised software tool. The case study organisations, however, believe that such tools are often developed by IT staff with little or no knowledge of construction. Thus, the resulting tool, although technically sound, may not necessarily facilitate the current process. It is thus important for software developers to understand the processes and working methods of the end-users for whom these tools are intended. There is, therefore, a need for more interaction between end-users and software development teams as this can equip the development teams with a better understanding of the end-user requirements and therefore develop a tool that best meets the user needs.

Techniques for Capturing and Storing Knowledge: Case study findings indicate that the techniques used vary not only from company-to-company, but also from department-todepartment. In most companies there are no standard procedures for knowledge capture and 
storage. Capture and storage of knowledge is seen of value to companies/departments with repetitive work processes and practices.

Post project reviews, discussion forums, mentoring and training are the KM techniques that are widely used to capture and store knowledge. The effectiveness of the techniques depends on several factors including the nature of work, type of construction company and its size, among others. A technique may sometimes be effective in one office of a company but not in another. Company 5, for example, uses a technique called peer mentoring that works well in their small offices because all staff members know each other on a personal basis. The same technique, however, was less effective in the company's regional head office where most staff were unfamiliar with the others roles and responsibilities. Company 5 observed the importance of 'social networks' and interactions for project success.

Another technique used by construction companies is that of post project reviews where project team members evaluate the project and identify the key success factors and problem areas (e.g. causes of bottlenecks, how these issues were addressed, by who, their impact on the project schedule, budget, etc). Such meetings are minuted and the review reports archived for future reference. Company 5 , for instance, organises regular project reviews both, during the project as well as after completion where project diaries that record the lifecycle history of projects are maintained. Currently, Company 5 documents these review reports on paper. E5 stressed that such stored data (in paper format) is of little or no value, if it is not available to others 'when they need it and where they need it'. Company 5 hopes to resolve this issue by maintaining electronic records that are available to all using the company intranet or other information sharing applications. At the end of the project, reports are filed manually for future reference. If this technique is to be effectively utilised, adequate time should be allocated for those involved in a project to participate. It is also crucial for post-project review meetings to take place immediately after a project is completed as project participants may move or be transferred to other projects or organisations.

\section{REPRESENTING KNOWLEDGE}

Knowledge may be represented either graphically or textually using different techniques and technologies. Knowledge mapping, for example, involves graphical representation of organisational procedures and processes. Also, company procedures and standards can be documented and represented textually either on paper or using technologies.

Technologies for Representing Knowledge: In most case study companies, knowledge about procedures is documented and represented using standard word processors e.g. MS Word. Spreadsheets are also used widely for numerical data (e.g. statistical data) and sometimes this data is represented graphically using charts and figures. 
Most case study companies do not use specialist IT-based tools such as knowledge mapping tools. Such tools are considered complex, cumbersome and restrictive. In their view, process mapping relies more on the expertise and experience of individuals undertaking the exercise rather than the software tools used (see Exhibit 3). In their view, most software tools provide very little intelligence or logic that is required to put together the information obtained. They rely on people to provide the correct information. For specialist tools with embedded 'intelligence', the implementation costs are often very high and not easily justified. There is also a level of risk involved in using new technologies, especially, if they have not been previously reviewed for their effectiveness. This is a risk most companies are not willing to take.

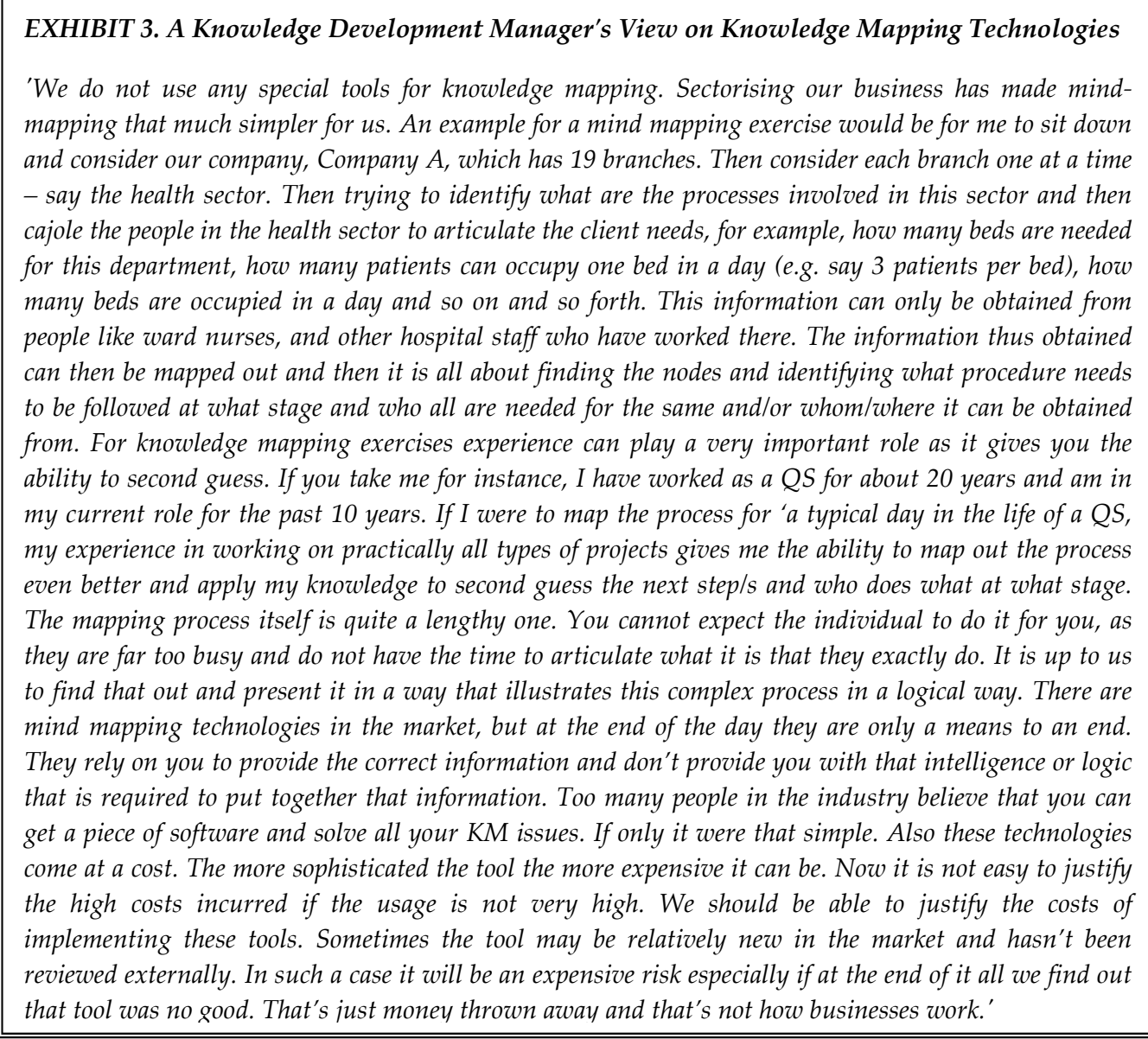

Techniques for Representing Knowledge: In most case study organisations, the use of knowledge mapping techniques is common compared to that of technologies. One of the most common techniques for mapping company processes and procedures involves brainstorming sessions during which discussions are held and the information obtained is recorded by placing 'post-it' notes on white boards. The effectiveness of this technique relies on the experience and 
expertise of staff involved in mapping the processes. Company 3 maps its processes by interviewing individuals involved in the process to identify what they do, how they do it and when and why. The data is represented in the form of 'skeleton' or 'fish bone' diagrams to which attributes are added. This is then documented in the form of charts and mind maps. At the next stage resources (human, financial, etc) necessary to perform individual tasks are identified including who is/are responsible for or linked to the tasks. These processes are streamlined till all the linkages are established in the resulting process map. Company 3 views this process of knowledge mapping to be helpful in capturing and representing knowledge about company processes and procedures in a format that is easy to understand and read.

\section{SHARING KNOWLEDGE}

Knowledge that has been captured and stored can be of little or no consequence if it cannot be shared with others. The various technologies and techniques used by case study companies to share knowledge are discussed below.

Technologies for Sharing Knowledge: Most case study companies were conventional in their use of technology primarily because of its impact on organisational culture. More often that not, technology adoption was met with resistance from staff who were directly affected by the implementation. This draws attention to the importance of a strategic approach to introducing changes. According to Company 1, for example, if the use of multimedia presentations for company promotions is demonstrated to staff, and they see the benefits of it, there is a good likelihood that they would emulate it themselves. If, however, the change is imposed, it is likely that it would be met with resistance. Thus, companies that plan to implement changes need to not only consider what the change is going to be, but also how it will be orchestrated.

The most commonly used technologies for sharing knowledge (both internally and externally) are technologies such as Web publishing tools, intranets, extranets and emails. The type of information shared using intranets, varied from company-to-company depending on their level of IT competency. Typical examples of the type of information that is available on company intranets include electronic company newsletters, advertisements, job vacancies, journals articles standard company forms and project reviews. Some companies adopt a proactive role in informing staff about upcoming events through e-mail notification. Externally, knowledge about company services or products is disseminated by publishing on dedicated company Web sites. Additionally, some case study companies (Companies 2, 4 and 5) use promotional methods such as multimedia presentations to clients for marketing the company's services and products. Others are actively involved with organisations such as CIRIA, BRE (Building Research Establishment) or similar industry outlets to market their services to construction audiences. 
The above examples draw attention to the type of knowledge companies share. Typically, this depends on the nature of the knowledge itself and its degree of sensitivity. Company 2, for instance, has a policy to record information about every sub-contractor and supplier they contract and their performance on projects. This information is documented and access is restricted to inhouse staff only. This documented information is beneficial to company-wide staff for selecting sub-contractors and/or suppliers on future projects. This saves the effort of carrying out subcontractor or supplier reviews before every appointment. In the next phase of implementation, Company 2 is considering making this information available to relevant supplier/sub-contractor organisations with the view of critically examining the data collected and identifying areas of improvement. In their view (Company 2s) such practices encourage continuous improvement among supply chain members through knowledge sharing.

Another widely used technology for knowledge sharing is the use of online collaboration tools or project extranets for managing construction projects. According to Company 2, collaboration tools facilitate improved coordination between project partners and enable development of long-term relationships between project partners. This increased collaboration encourages knowledge sharing among project teams. The effectiveness of this tool largely depends on the commitment of the project partners. Company 3 runs virtual communities using a Web-based extranet tool, which provides a framework for running the community. It enables specialists to get together and operate open interactive forums. Thus, companies can set up communities of like-minded people, either from within the organisation or outside and also invite people to join the virtual community and/or share experiences, ideas and documents. Technologies such as extranets function mainly as 'facilitators', rather than drivers. Since the development of such virtual communities is still in its infancy, it has been difficult to evaluate their usefulness and effectiveness.

Techniques for Sharing Knowledge: The most common techniques used by construction companies to share knowledge include face-to-face interactions and discussion forums where knowledge is shared directly through dialogues and discussions. Different channels of communication can be used for sharing knowledge. For sharing knowledge about a company's competency, for example, company magazines or newsletters can be distributed either electronically or in paper format. Typically, these newsletters include information about a company's projects, services and activities. It should, however, be noted that the growing popularity of electronic media, its relative cost effectiveness and the speed of delivery are driving companies to favour electronic media for sharing knowledge.

Some other techniques for knowledge sharing include hosting events for which experts are invited to deliver talks and share their knowledge. The question and answer sessions that follow are often used to obtain expert opinion on current and impending problem. Other 
techniques of knowledge sharing include publicising company products and services through press releases and news articles in construction journals and magazines, sponsoring construction events such as conferences, lecturing at universities to target future construction professionals.

Company 4 extensively uses communities of practice for knowledge sharing. According to Company 4 most communities are subject-specific communities, e.g. HR, finance, etc., and employees use these communities irrespective of the projects they are involved in. Membership to these communities is voluntary. In most cases people are willing to join such communities because they need to find answers to their questions and acquire help and guidance from peers. However, the success of this technique depends on the attitude of the different members of the community. Questions asked by members of the communities need to be viewed objectively by all, no matter how basic they may seem. There have been instances in some communities where some questions put forth by one member were viewed as 'mundane questions' by another. Such an unconstructive attitude is viewed as derogatory which discourages participation in the community and is thus detrimental to its success and functioning.

Apprenticeship, which involves a 'learning by doing' approach, is another technique that is used to share knowledge. Companies view this technique to be beneficial to both the apprentice and to itself. A fresh graduate, for example, can bring in a 'fresh approach' and new ideas into the company.

\section{CREATING KNOWLEDGE}

The case study organisations do not adopt a structured approach for knowledge creation. The approach is mainly ad hoc. Most case study companies were opposed to the idea of developing a formalised structure for creating new knowledge. In their view creativity is best when left fluid and flexible. Having a rigid, structured approach for knowledge creation can inhibit creativity. In their view, companies can adopt a structured approach if the need arises, but when left fairly unstructured, knowledge creation accommodates levels of enthusiasm, time and commitment from those participating. Also, the type of approach adopted can vary according to the type of the business operations. In construction companies with repetitive operations, there is some evidence of a structured approach for knowledge creation and also a continuous improvement culture. They are constantly measuring performance and reviewing what actions need to be undertaken to improve the process from one project to another and thus the business performance. Also, in such situations the investment costs are easier to justify as the process improvement is faster and clearly visible. However, for projects that are repeated over longer durations (say five years), the justification of costs can be difficult. Some of the technologies and techniques used to create new knowledge are discussed below.

Technologies for Creating Knowledge: Among case study companies there is very 
little incentive to use specialised technologies for knowledge creation. The common consensus was that it is difficult to justify the ROI (Return on Investment) for using 'expensive and fancy' tools for actual profit improvement within their organisations. Most companies believe that there is more value in using standard software applications like MS Work Suite.

Only companies with a defined knowledge strategy have begun the process of implementing technologies that can aid in the process of creating knowledge. One company (Company 4) has developed a knowledge Web within its intranet. Using this tool, queries can be posted onto the intranet which in turn can be viewed by users of the intranet. Relevant people can respond to these queries, just contributing to new knowledge. It is, however, seen that there is currently very little incentive for staff members to respond to such queries and responses are currently being received from only a handful of enthusiastic staff members. In order to improve the response rate there is a need to incentivise staff. Company 4 has addressed this by incorporating KM into their appraisal and rewards scheme. In their view, rewards need not be of financial nature. Recognition and promotion can be the means through which good KM practices are rewarded.

Techniques for Creating Knowledge: A majority of the case study organisations tend to use techniques such as brainstorming sessions, and face-to-face interactions for knowledge creation. In addition, knowledge communities and workshops are also used extensively to support knowledge creation. Techniques such as project close-out meetings are also used. At such meetings, client feedback (e.g. recommendations to improve performance or service-delivery) is encouraged.

Another technique adopted by Company 1, is a technique called 'knowledge profiling' for which people from different client sectors (e.g. the Health Sector) are surveyed, to establish what they do, why/how they do it, and what they know. This is not a formal assessment of people skills and capabilities. The main objective of 'knowledge profiling' is to understand the day-to-day working (including procedures followed, resources used, etc) of staff members and documenting this information in an accessible format that can be used by all - thus creating new knowledge. The knowledge thus created gives a better understanding of the different processes and procedures involved to perform routine activities and can be used by anyone who is new to that activity.

\section{SUMMARY AND CONCLUSIONS}

This paper began with a review of KM technologies and techniques. It then investigated with the help of case studies the integrated use of these $\mathrm{KM}$ technologies and techniques for managing knowledge in UK construction organisations. From the case studies it is evident that the use of 
$\mathrm{KM}$ techniques for managing $\mathrm{KM}$ processes is more common compared to $\mathrm{KM}$ technologies. This is in spite of the fact that a myriad of technologies are currently available to support the different $\mathrm{KM}$ processes. This finding is hardly surprising, given that $\mathrm{KM}$ techniques are affordable to most organisations since very little sophisticated infrastructure is required. Also, KM techniques are easy to implement and maintain due to their simple and straightforward nature. KM technologies, on the other hand, depend heavily on an IT infrastructure. There is also a level of scepticism associated with technology adoption, especially in construction companies, which could be attributed to the fact that there is a general lack of understanding of the potential benefits of KM technologies. Most organisations view technologies as a means to an end and are therefore reluctant to invest in specialist KM technologies. Given that most case study organisations do not fully understand the potential benefits of technologies and techniques for $\mathrm{KM}$, they could benefit from the documentation of the efficacy of different techniques and technologies for knowledge management in given contexts, together with a framework for evaluating the performance of knowledge management techniques and technologies.

Organisations only adopt KM technology if there are definite, quantifiable business benefits which stretch across the organisation. The case study organisations believe that KM technologies are often developed by IT staff who have little or no knowledge of construction processes and therefore, the resulting tool although technically sound, may not necessarily facilitate the current process. Therefore, it is important for developers of KM technologies to fully understand the processes and working methods of the end-users for whom these tools are developed. Furthermore, cost, flexibility and functionality are considered as the three factors that influence their decision to select technologies, with cost being the most important of the three. It is essential that KM technology providers take the 'cost' issue into account if they are to sustain long-term competitiveness.

A consistent story unfolds from the case studies discussed in this paper. Many of the insights recorded are both confirmed and extended by the findings. For example, it is evident that the case study organisations do not adopt a structured approach for selecting KM technologies and techniques. They are therefore, open to interpretation. Also, way these techniques are selected does not link the selection process to the organisational goals for implementing KM. The current approach is mainly ad hoc and reactive to short-term business needs. In some case study companies, for example, specially appointed members of staff review different KM technologies and select the ones that best meet their business needs. In construction companies with repetitive operations, however, there is some evidence of a structured approach for knowledge creation. Such 'impulsive quick fixes' may work in the short-term; however, there is a need for planned long-term strategies that not only take into account the immediate business needs, but also the business's emerging needs. Clearly, construction organisations need to recognise that 
$\mathrm{KM}$ technologies and techniques are necessary for addressing their $\mathrm{KM}$ problem and it is imperative that in any given situation they adopt an integrated approach for using KM techniques and technologies. A careful analysis of the requirements for KM is vital in this regard.

\section{REFERENCES}

1. Al-Ghassani, A.M. (2002), Literature Review on KM Tools, Technical Report, July 2002, Department of Civil and Building Engineering, Loughborough University, UK.

2. Anumba, C.J., Bloomfield, D., Faraj, I. and Jarvis, P. (2000), 'Managing and Exploiting Your Knowledge Assets: knowledge based decision support techniques for the construction industry', BR382, Construction Research Communications Ltd., UK.

3. Brown, J. S. and Duguid, P. (1991) 'Organizational learning and communities of practice: towards a unified view of working, learning and organization', Organization Science, Vol. 2, No. 1, pp. 40-57.

4. Carrillo, P.M. (2001). Mergers and Acquisitions in the Construction Industry: An Exploratory Study, PhD Thesis, Loughborough University, 2001.

5. Carrillo, P.M., Robinson, H. S., Al-Ghassani, A.M. and Anumba, C.J. (2002). 'Survey of Knowledge Management in Construction', KnowBiz Project Technical Report, Department of Civil and Building Engineering, Loughborough University, UK.

6. Chataway, J.C., Gault, F., Quintas, P. and Wield, D.V. (2003) 'Dealing with the Knowledge Divide' in G. Sciadas (Ed.) Monitoring Digital Divides and Beyond, Orbicom, Montreals

7. Davenport, T. H. and Prusak, L. (1998), 'Working Knowledge: how organisations manage what they know', Boston: Harvard Business School Press.

8. Egan, J., Sir (1998). 'Rethinking Construction', [online], Available from: http://www.construction.detr.gov.uk/cis/rethink/index.htm. (Accessed 05 November, 2003)

9. Egbu, C. O., (1999). 'The Role of Knowledge Management and Innovation in Improving Construction Competitiveness' Building Technology and Management Journal, Vol. 25, pp. 1-10.

10. Egbu, C. O., (2000). 'Knowledge Management in Construction SME's: Coping with the Issues of structure, Culture, Commitment and Motivation'. Proceedings of the $16^{\text {th }}$ Annual Conference of ARCOM, 6 - 8 September, Glasgow Caledonian University, UK. Vol. 1, pp. $83-92$.

11. Egbu, C. O. (2000a), 'The Role of IT in Strategic Knowledge Management and its Potential in the Construction Industry', UK National Conference on Objects and Integration for Architecture, Engineering, and Construction, 13-14th March, BRE, Watford, UK. 
12. Egbu, C., and Robinson, H., (2005). Construction as a Knowledge-Based Industry, Knowledge Management in Construction, Edited By C. J. Anumba, C. Egbu and P. Carrillo, Blackwell Publishing, Oxford, UK.

13. Gallupe, R.B. (2001), Knowledge Management Systems: Surveying the Landscape, International Journal of Management Reviews, Vol. 3, No. 1, March, pp 61-67.

14. Haag. S., Cummings M., and Dawkins, J. (1998), Management Information Systems for the Information Age, McGraw-Hill, USA.

15. Haag, S. and Keen, P. (1996), Information Technology: Towards Advantage Today, McGraw-Hill, USA.

16. Hansen, M.T., Nohria, N., and Tierney, T. (1999), What's Your Strategy for Managing Knowledge, Harvard Business Review, March-April.

17. Hari, S., Egbu, C. O., and Kumar, B., (2003). 'Knowledge Management for Small and Medium Enterprises - Issues Concerning Culture and Information Technology'. Proceedings of the $2^{\text {nd }}$ International Conference on Innovation in Architecture, Engineering and Construction, $25-27^{\text {th }}$ June 2003, Loughborough, U.K., pp. $569-580$.

18. Hippel, E. von (1994) "'Sticky information" and the locus of problem solving: implications for innovation', Management Science, Vol. 40, No. 4, 429-439.

19. Kamara, J.M., Anumba, C.J. and Carrillo, P.M. (2002), 'A CLEVER Approach to Selecting a Knowledge Management Strategy', International Journal of Project Management, 20(3), 2002, pp 205-211.

20. Kanter, J. (1999), Knowledge Management: practically speaking, Information Systems Management, Fall 1999, pp 7-15.

21. KPMG Management Consulting, (1998). Knowledge Management Research Report KPMG Management Consulting.

22. Lang J. C. (2001), Managerial Concerns in Knowledge Management, Journal of Knowledge Management, Vol., Number 1, pp 43-57.

23. Lave, J. and Wenger, E. (1991) Situated Learning: Legitimate Peripheral Participation, Cambridge University Press, Cambridge.

24. Lucca, J., Sharda, R. and Weiser, M. (2000), Coordinating Technologies for Knowledge Management in Virtual Organisations, Proceedings of the Academia/Industry Working Conference on Research Challenges CAIWORC'00, 27-29 April, Buffalo, New York.

25. Latham, M., Sir (1994). 'Constructing the Team'. Final report of the government/industry review of procurement and contractual arrangements in the UK construction industry, HMSO, London.

26. Nissen, M., Kamel, M., Sengupta, K. (2000), "Integrated analysis and design of knowledge systems and processes", Information Resources Management Journal, Vol. 
13 No.1, pp.24-43.

27. Polanyi, M. (1958) Personal Knowledge, Routledge and Kegan Paul. London.

28. Polanyi, M. (1966) The Tacit Dimension, Doubleday, Garden City, NY.

29. Quintas, P. (2005). The Nature and Dimensions of Knowledge Management, Knowledge Management in Construction, Edited By C. J. Anumba, C. Egbu and P. Carrillo, Blackwell Publishing, Oxford, UK.

30. Robinson, H. S., Carrillo, P. M., Anumba, C. J., and Al-Ghassani, A. M. (2001). ' Linking Knowledge Management Strategy to Business Performance in Construction Organisations', Proceedings of the $17^{\text {th }}$ Annual Conference of the Association of Researchers in Construction Management (ARCOM), Akintoye, A. (Ed), University of Salford, 5-7 September 2001, Vol. 2, pp 577-586.

31. Ruggles, R. (1997), 'Knowledge Tools: Using Technology to Manage Knowledge Better', Working paper for Ernst and Young, [online], Available from: http://www.businessinnovation.ey.com/mko/html/toolsrr.html Accessed 16 August, 2000.

32. Santosus, M., and Sarmacz, J., (2001). 'The ABCs of Knowledge Management', [online], Available from: - http://www.cio.com/research/knowledge/edit/kmabcs.html Accessed 17 January, 2004.

33. Scarborough, H., Swan, J. and Preston, J., (1999). Knowledge Management a Literature Review - Issues in People Management, London Institute of Personnel and Development.

34. Skyrme, D.J. and Amidon, D. A. (1997), A Report on: Creating the Knowledge-Based Business. Business Intelligent Limited, London.

35. Storey, J. and Barnet, E. (2000), Knowledge Management Initiatives: learning from failure, Journal of Knowledge Management, Vol. 4, No. 2, pp 145-156.

36. TFPL Ltd., (1999). 'A report on: skills for knowledge management - building a knowledge economy.' London, $1^{\text {st }}$ Edition.

37. Tsui, E. (2002a), Technologies for Personal and Peer to Peer (P2P) Knowledge Management, CSC Leading Edge Forum Technology Grant Report $<$ http://www2.csc.com/lef/programs/grants/finalpapers/tsui_final_P2PKM.pdf > [06/06/02].

38. Tsui, E. (2002b), Tracking the Role and Evolution of Commercial Knowledge Management Software, in Handbook on Knowledge Management, C.W. Holsapple (ed), Springer-Verlag, Berlin/Heidelberg.

39. Tiwana, A. (2000), The Knowledge Management Toolkit, New Jersey: Prentice Hall Inc. USA.

40. Yin, R. K. (1994). Case Study Research: Design and Methods (Second Edition) Thousand Oaks, CA: Sage, 1994. 
